\title{
Mechanical behaviour of sand stabilised with colloidal silica
}

Vasiliki N. Georgiannou MSC, DIC, PhD

Associate Professor, School of Civil Engineering, National Technical University of Athens, Athens, Greece (corresponding author: vngeor@civil.ntua.gr)

\author{
Eleni-Maria Pavlopoulou MSc \\ PhD candidate, School of Civil Engineering, National Technical University of \\ Athens, Athens, Greece \\ Zisis Bikos MEng \\ Graduate student, School of Civil Engineering, National Technical University \\ of Athens, Athens, Greece
}

The response of sand stabilised with colloidal silica aqueous gel is examined in the laboratory, under direct shear, triaxial and normal compression loading, in comparison to that of untreated sand of similar density to evaluate the effect of stabilisation on subsequent sand response. The behaviour of the treated sand differs in important respects from the behaviour of the untreated sand: a significant increase in the angle of shearing resistance is observed at lower stress levels, diminishing with increasing stress level; the peak strength envelope is curved at low stresses for the treated sand only, while at ultimate strength, the envelopes coincide for treated and untreated sands. However, at all stress levels, extreme dilation is associated with the treated sand at peak and ultimate strength conditions. Under normal compression, the treated sand is easily densified, exhibiting higher compressibility than that of sand of similar density. It appears that depending on loading conditions, the aqueous gel alters its structure and has the capacity to absorb or discharge free water; it is of paramount importance to measure volume change and/or pore water pressure change during stabilised sand testing.

\section{Notation}

$A_{\mathrm{c}} \quad$ corrected area

$A_{\mathrm{i}} \quad$ initial area

$B \quad$ Skempton's parameter

C cohesion

$D_{50} \quad$ mean particle size

e void ratio

$e_{\mathrm{i}} \quad$ initial void ratio (at the end of consolidation)

$e_{\max }$ maximum void ratio

$e_{\text {min }}$ minimum void ratio

$e_{\mathrm{p}} \quad$ void ratio at peak strength

$G_{\mathrm{s}} \quad$ specific gravity

$p^{\prime} \quad$ mean effective stress

$p_{\mathrm{i}}^{\prime} \quad$ initial mean effective stress (at the end of consolidation)

$q \quad$ deviatoric stress

$q_{\text {ucs }} \quad$ unconfined compressive strength

$x \quad$ horizontal displacement

$y \quad$ vertical displacement

$\delta_{\mathrm{h}} \quad$ horizontal displacement

$\varepsilon_{\mathrm{a}} \quad$ axial strain

$\varepsilon_{\mathrm{vol}} \quad$ volumetric strain

$\sigma_{\mathrm{v}}^{\prime} \quad$ current normal effective stress

$\sigma_{\mathrm{vo}}^{\prime} \quad$ initial normal effective stress

$\tau \quad$ shear stress

$\tau_{\text {cyc }} \quad$ single-amplitude cyclic shear stress

$\phi_{\mathrm{p}} \quad$ angle of shearing resistance at peak strength

$\phi_{\mathrm{u}} \quad$ angle of shearing resistance at ultimate strength

\section{Introduction}

Soil improvement techniques have traditionally been implemented in liquefiable soils (Seed and Lee, 1966) to increase their liquefaction resistance and limit deformations. Dynamic compaction, vibrocompaction, vibroflotation and pressure grouting of cement, clay and/or other chemical solutions through a network of boreholes have been successfully applied in the field (D’Appolonia et al., 1955; Donovan et al., 1984; Maher et al., 1994; Mayne et al., 1984). The first three methods provide direct control on the density of a sand deposit but may not be feasible in developed sites where methods based on grouting may be more suitable. In recent years, a new 'passive site stabilisation' method has been proposed for the remediation of liquefaction potential in developed sites under least disturbance (Gallagher and Mitchell, 2002). In this method, a colloidal silica (CS) solution is introduced in the water regime at a hydrologically upgradient site, and the CSinfused groundwater flows onto the target sand deposit. Alternatively, a flux of the solution can be induced in the ground depending on the hydraulic conductivity of the deposit; the feasibility of this method has been examined in field tests reported by Gallagher et al. (2007).

To evaluate the role of CS on subsequent sand behaviour, a number of laboratory studies have been performed concentrating on undrained cyclic tests to determine the resistance of the treated sand to liquefaction. In most of these studies (Gallagher and Mitchell, 2002; Towhata and Kabashima, 2001), liquefaction resistance is defined by a threshold set in strain accumulation during cyclic loading without measurements of generated excess pore water pressure. Other studies resort to simple shear tests under constant volume conditions to eliminate the shortcomings of pore pressure development during undrained loading (DíazRodríguez et al., 2008; Finn and Vaid, 1977). Fewer studies report pore pressure measurements during undrained cyclic loading. Porcino et al. (2011) found that depending on the loading mode, the pore pressure development curves for treated sand 
differ significantly in simple shear and triaxial testing; showing in the former a trend similar to untreated sand. Kodaka et al. (2005) measured identical excess pore water pressure accumulation for treated and untreated sands up to the onset of liquefaction for the untreated sand, at an excess pore water pressure ratio of 0.6 . Further increase to an excess pore water pressure ratio of 1.0 was observed for the untreated sand only. For sands, pore pressure development is not affected by the loading mode (Georgiannou and Tsomokos, 2008; Seed et al., 1975). Given the affinity of CS to water, due to its enormous surface (Bergna and Roberts, 2005), it is of paramount importance to measure and/or control the pore water pressure during the tests.

When stabilised with CS aqueous gel, sands generally exhibit significant gain in their liquefaction resistance, due to the supporting role of the silica gel filling the pores. However, CS impregnation results in a significant increase in resistance as the initial effective stress increases and only a mild increase at low stress levels $\left(\sigma_{\mathrm{v}}^{\prime}<\right.$ $50 \mathrm{kPa}$ ) in simple shear tests (Díaz-Rodríguez et al., 2008). On the other hand, Porcino et al. $(2011,2012)$ observed a significant increase in liquefaction resistance at high cyclic stress ratios $\left(\mathrm{CSR}=\tau_{\text {cyc }} / \sigma_{\mathrm{v}}^{\prime}\right)$ only, which diminishes at lower CSR values under both simple shear and triaxial tests. This observation is supported by monotonic triaxial tests which show a significant increase in the peak shear strength accompanied by dilation only at low stress levels of $p_{\mathrm{i}}^{\prime}<100 \mathrm{kPa}$; however, the trend reverses in simple shear tests where only the treated specimens at $\sigma_{\mathrm{v}}^{\prime}>100 \mathrm{kPa}$ show higher peak stress ratios and dilation compared to untreated sand specimens. These discrepancies may indicate an effect of loading mode and/or stress level on the support provided by the CS grout on the sand grains, which needs to be addressed conclusively.

The formation of artificial bonds between sand grains in the form of cementation is consistent with expectations. However, the significant increase in the resistance of the treated compared to untreated sand observed only at higher stress levels appears to be counterintuitive. Wang and Leung (2008) tested cement-treated sands and suggested that bond-breaking is counteracted by the production of clusters of particles contributing to increased dilation. The assessment of the applicability of such mechanisms to CS-treated sands is essential and valuable.

In this paper, the strength envelope of CS-treated sand is determined within a wide range of confining stresses by tests performed in the direct shear box and the triaxial apparatus under drained loading conditions. Only drained triaxial tests are presented for direct comparison with the shear box tests. The strength envelopes are compared for treated and untreated sands while the loading mode effect is assessed. The effect of stress level is identified for the treated sand and is used for the interpretation of its response to shearing relative to untreated sand. Moreover, the response of the treated sand at various stress levels is interpreted as indirect evidence of the existence and the evolution of the CS gel and sand particles' interaction. Supporting evidence is also provided by the comparison of the response of the treated sand to isotropic and one-dimensional (1D) consolidation and microscope image analysis.

\section{Materials and testing methods}

The M31 sand tested in this study is a medium fine sand, with a mean particle diameter of $D_{50}=0.31 \mathrm{~mm}, e_{\min }=0.505, e_{\max }=$ $0 \cdot 844$ and $G_{\mathrm{s}}=2 \cdot 66$. The grading curve of the sand is shown in Figure 1. Ludox SM-30 was selected as the stabilising agent of specimens, supplied as a $30 \%$-by-weight silica aqueous solution (hydrosol) with a viscosity of $5.5 \mathrm{cP}(1 \mathrm{cP}=1 \mathrm{mPa} \mathrm{s})$, a $\mathrm{pH}$ of 10 and an average particle size of $7 \mathrm{~nm}$. Distilled water was added to the initial hydrosol in order to obtain a CS concentration of $10 \%$ by weight and sol viscosity that is little above $1 \mathrm{cP}$. Electrolyte (sodium chloride $(\mathrm{NaCl})$ ) and acid (hydrochloric acid $(\mathrm{HCl})$ ) were added to adjust the ionic strength to a value of $0.03 \mathrm{~N}$ and the $\mathrm{pH}$ level to 6 . Under these conditions, the sol thickens quickly as the colloidal particles collide and siloxane bonds are formed. The gel time was defined as the time needed for the viscosity to rise above $100 \mathrm{cP}$, which is a threshold for a further exponential increase in viscosity. The gel time was calculated to be $10 \mathrm{~h}$ for the $10 \% \mathrm{CS}, 0.03 \mathrm{~N}$ and $\mathrm{pH}=6$ hydrosol (Agapoulaki and Papadimitriou, 2015).

The water sedimentation method is used to prepare the sand specimens; this method yields uniform and repeatable specimens with a fabric similar to that of natural deposits (Vaid et al., 1999). Treated sand specimens are formed by the sedimentation of the dry sand through the hydrosol. After $50 \mathrm{~h}$ of curing in isolated conditions at room temperature, the colloidal hydrosol forms a gel allowing handling of the specimen. In the inset photograph in

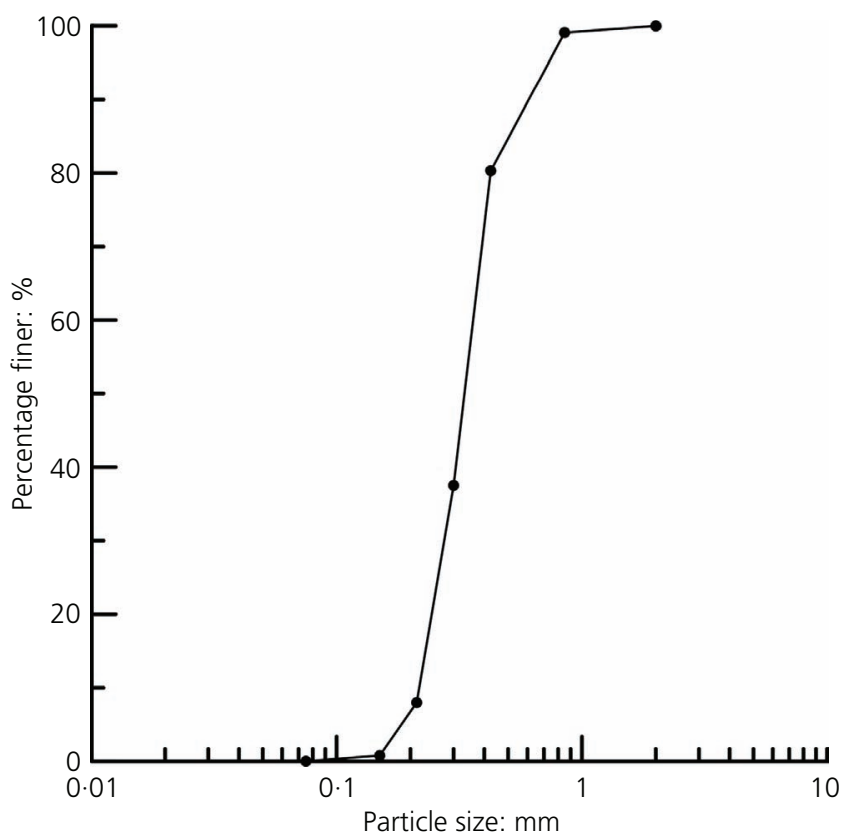

Figure 1. Grain size distribution curve of M31 sand 


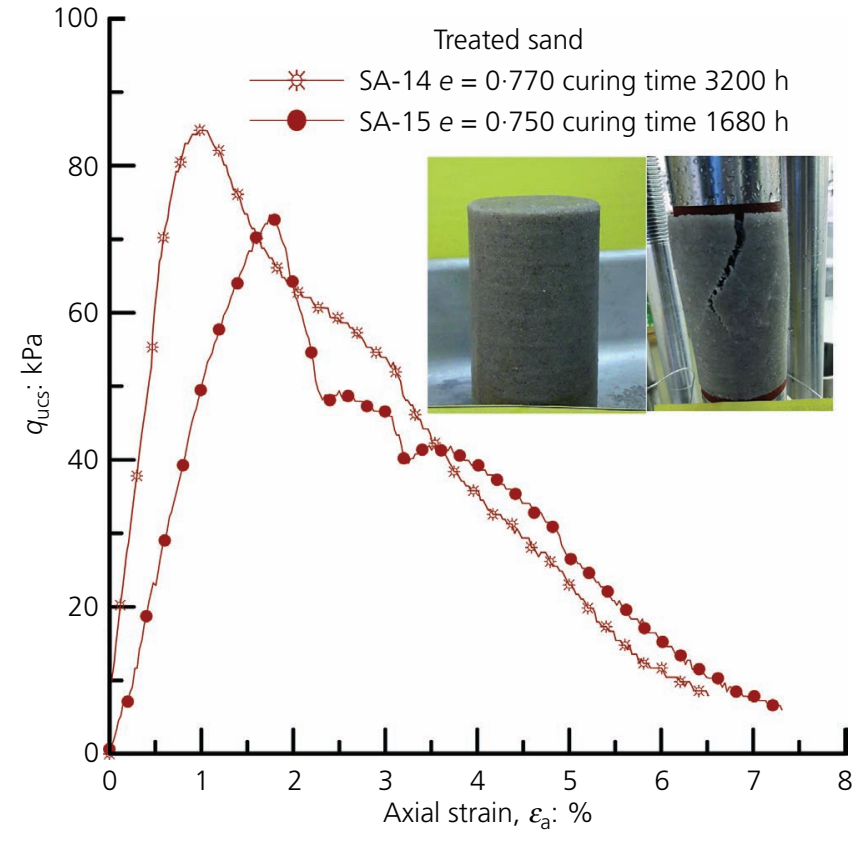

Figure 2. Unconfined compression test results on treated M31 sand

Figure 2, a treated specimen is shown before and after an unconfined compression test. In triaxial tests, the prepared treated specimens are formed to the target density in split moulds with a diameter of $50 \mathrm{~mm}$ and a height of $100 \mathrm{~mm}$. In the case of direct shear, the samples had a diameter of $60 \mathrm{~mm}$ and were approximately $24 \mathrm{~mm}$ high. Specimens for oedometer tests are formed within the apparatus in a similar fashion to triaxial specimens by filling the oedometer ring with hydrosol followed by sand sedimentation.

Triaxial tests were performed on a high-pressure triaxial cell with maximum cell pressure of $7 \mathrm{MPa}$ and maximum axial load of $50 \mathrm{kN}$. The overall stability of the system in terms of pressure measurements is $0 \cdot 1 \mathrm{kPa}$ for cell pressures of up to $4 \mathrm{MPa}$ and $0.5 \mathrm{kPa}$ for higher pressures. The high values of confinement allow the application of relatively high initial values of back pressure $(300-700 \mathrm{kPa})$; these are required to check potential damage to the gel due to increasing values of back pressure in drained tests and to prevent cavitation in their undrained counterparts. The results are shown to be independent of the values of back pressure. All specimens are saturated with $B$ values greater than 0.97 .

The treated specimens exhibit an unconfined compressive strength $q_{\text {ucs }}$ of $\sim 80 \mathrm{kPa}$ when sheared with a strain rate of $0 \cdot 2 \% / \mathrm{min}$, after a curing time of 1680 and $3200 \mathrm{~h}$ as shown in Figure 2. Strength increases with curing time by approximately $15 \%$ for a period of 2 months. Photographs of specimen SA-14 before and after testing are included in the figure. In the shear box and the triaxial apparatus, strain rates of 0.005 and $0.025 \mathrm{~mm} / \mathrm{min}$, respectively, were applied during drained loading. Area corrections were made to stresses following the right cylinder assumption for the triaxial and using Equation 1 for the shear box tests according to Bareither et al. (2008)

1. $A_{\mathrm{c}}=A_{\mathrm{i}}\left[\frac{1}{90} \times \cos ^{-1}\left(\frac{\delta_{\mathrm{h}}}{D}\right)-\frac{2}{\pi} \times \frac{\delta_{\mathrm{h}}}{D} \times \sqrt{1-\left(\frac{\delta_{\mathrm{h}}}{D}\right)^{2}}\right]$

where $A_{\mathrm{c}}$ is the corrected area, $A_{\mathrm{i}}$ the initial area, $\delta_{\mathrm{h}}$ is the horizontal displacement and $D=60 \mathrm{~mm}$ is the diameter of the shear box.

\section{Test results}

The results of direct shear tests are shown in Figure 3 for sand at loose, medium and dense states. Details of the specimens are included in Table 1. Typical sand response is observed with a peak stress ratio depending on density, being higher for the higher-density specimens and reducing with increasing void ratio independent of stress level. The volumetric behaviour of the medium density sand $\left(e_{\mathrm{i}}=0 \cdot 641-0 \cdot 656\right)$ is shown in Figure 3(b). After initial contraction, the sand specimens dilate, exhibiting lower vertical displacement compared to that of the dense specimen $e_{\mathrm{i}}=0.550$, while dilation is very small for the loosest specimen at $e_{\mathrm{i}}=0.696$. The angle of shearing resistance, which can be defined within $\pm 0 \cdot 10^{\circ}$ (Bareither et al., 2008) has been determined in Figure 4 for peak strength and ultimate strength conditions. The corresponding values are $\phi_{\mathrm{p}}=32.5^{\circ}$ and $\phi_{\mathrm{p}}=$ $36.7^{\circ}$ for medium-density (A-1, A-5, A-9, A-10) and dense (A-2, A-7, A-11) specimens, respectively, included in Table 1, while a common $\phi_{\mathrm{u}}=30 \cdot 3^{\circ}$ is obtained at ultimate strength conditions for all densities, a value similar to the peak strength observed for the loosest specimen $e_{\mathrm{i}}=0.696$ sheared at $\sigma_{\mathrm{v} 0}^{\prime}=125 \mathrm{kPa}$ and included in Figure 4.

The response of the treated sand at medium density $e_{\mathrm{i}}=0.644 \pm$ 0.01 is examined next. In Figure 5, the stress ratio and vertical displacement are plotted against the horizontal displacement for a small normal stress range $\sigma_{\mathrm{v} 0}^{\prime}=196-268 \mathrm{kPa}$. The results nearly coincide. However, when the normal stress range is expanded, both stress ratio and dilation potential are significantly altered as indicated in Figure 6, increasing at the lowest, $\sigma_{\mathrm{v} 0}^{\prime}=125 \mathrm{kPa}$, and decreasing at the highest, $\sigma_{\mathrm{v} 0}^{\prime}=555 \mathrm{kPa}$, normal stresses. This stress level dependency may be associated with destructuration and is a characteristic response of the treated sand only, being negligible for the untreated loose sand included in Figure 6 for comparison. Figure $6(\mathrm{~b})$, where the corresponding curves for untreated sand at $\sigma_{\mathrm{v} 0}^{\prime}=125$ and $555 \mathrm{kPa}$ are also included for comparison, shows that irrespective of stress level, the treated specimens initially contract, slightly less than sand with the same density, and subsequently dilate under extremely high dilatancy rates at peak strength, dilating at ultimate strength by more than four times the sand specimens. This enhanced dilation has been consistently observed in the literature where the 


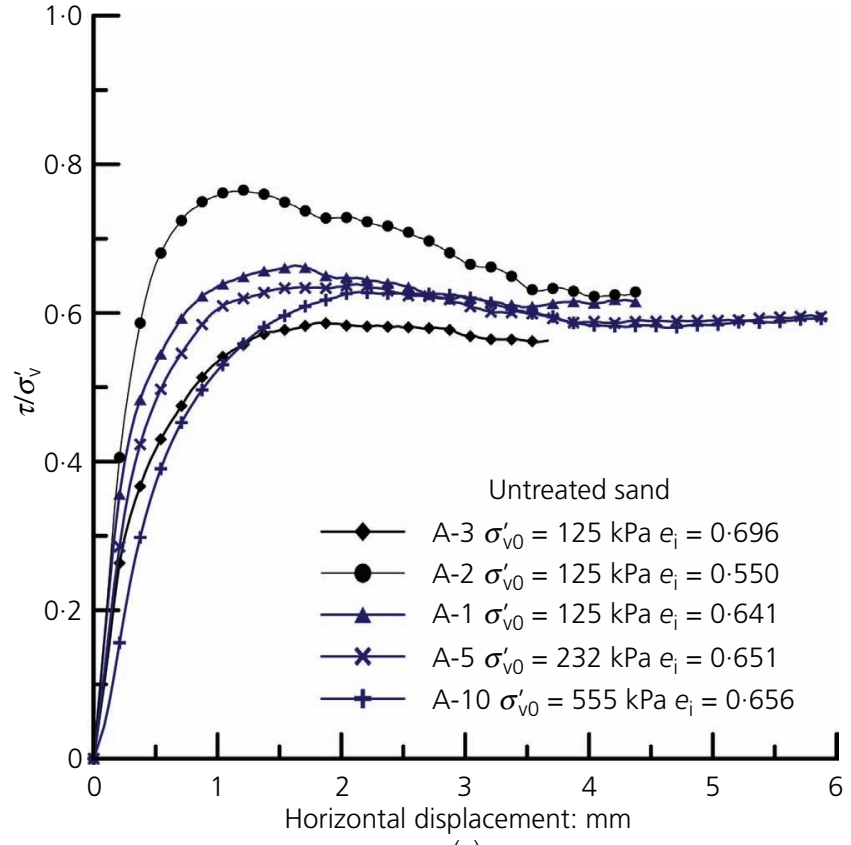

(a)

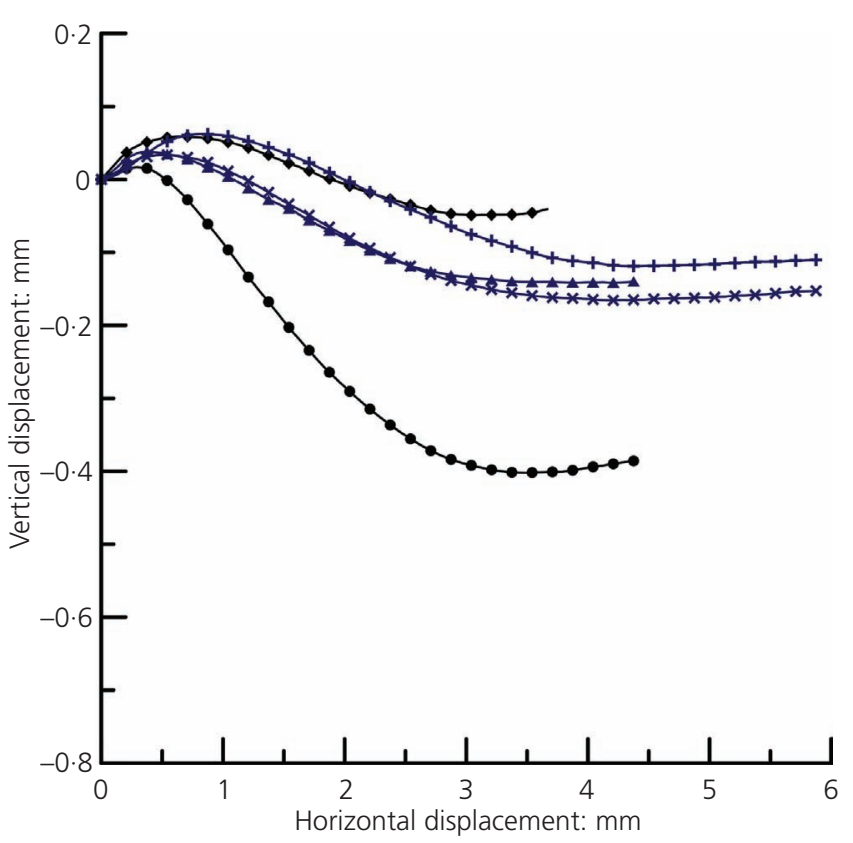

(b)

Figure 3. Direct shear tests on M31 sand: (a) stress ratio $\tau / \sigma_{v}^{\prime}$ against horizontal displacement curves; (b) vertical against horizontal displacement curves

Table 1. Specimen characteristics

\begin{tabular}{|c|c|c|c|c|c|c|c|c|c|}
\hline Test & Test type & $e_{i}$ & $e_{p}$ & $\sigma_{\mathrm{v} 0}^{\prime}: \mathrm{kPa}$ & $p_{\mathrm{i}}^{\prime}: \mathrm{kPa}$ & $\tau / \sigma_{v}^{\prime}$ & $q / p^{\prime}$ & qucs: kPa & $\mathrm{U} / \mathrm{T}$ \\
\hline$A-1$ & DS & 0.641 & 0.638 & 125 & - & 0.665 & - & - & $U$ \\
\hline A-2 & DS & 0.550 & 0.542 & 125 & - & 0.766 & - & - & U \\
\hline A-3 & DS & 0.696 & 0.696 & 125 & - & 0.587 & - & - & $U$ \\
\hline$A-4$ & DS & 0.535 & 0.524 & 125 & - & 0.758 & - & - & $U$ \\
\hline A-5 & DS & 0.651 & 0.646 & 232 & - & 0.641 & - & - & U \\
\hline A-6 & DS & 0.661 & 0.656 & 232 & - & 0.612 & - & - & $U$ \\
\hline A-7 & DS & 0.528 & 0.523 & 232 & - & 0.749 & - & - & $U$ \\
\hline A-8 & DS & 0.626 & 0.618 & 232 & - & 0.729 & - & - & U \\
\hline A-9 & DS & 0.658 & 0.653 & 340 & - & 0.650 & - & - & U \\
\hline A-10 & DS & 0.656 & 0.655 & 555 & - & 0.630 & - & - & $U$ \\
\hline A-11 & DS & 0.554 & 0.547 & 555 & - & 0.742 & - & - & U \\
\hline SA-1 & DS & 0.655 & 0.621 & 53 & - & 0.835 & - & - & $\mathrm{T}$ \\
\hline SA-2 & DS & 0.639 & 0.623 & 125 & - & 0.877 & - & - & $\mathrm{T}$ \\
\hline SA-3 & DS & 0.637 & 0.619 & 196 & - & 0.857 & - & - & $\mathrm{T}$ \\
\hline SA-4 & DS & 0.647 & 0.631 & 232 & - & 0.824 & - & - & $\mathrm{T}$ \\
\hline SA-5 & DS & 0.612 & 0.600 & 232 & - & 0.884 & - & - & $\mathrm{T}$ \\
\hline SA-6 & DS & 0.643 & 0.625 & 268 & - & 0.789 & - & - & $\mathrm{T}$ \\
\hline SA-7 & DS & 0.646 & 0.623 & 340 & - & 0.770 & - & - & $\mathrm{T}$ \\
\hline SA-8 & DS & 0.681 & 0.676 & 340 & - & 0.723 & - & - & $\mathrm{T}$ \\
\hline SA-9 & DS & 0.632 & 0.625 & 555 & - & 0.698 & - & - & $\mathrm{T}$ \\
\hline A-12 & TR-D & 0.710 & 0.716 & - & 200 & - & 1.33 & - & U \\
\hline A-13 & TR-D & 0.717 & 0.718 & - & 300 & - & $1 \cdot 30$ & - & U \\
\hline A-14 & TR-D & 0.691 & 0.693 & - & 500 & - & $1 \cdot 31$ & - & $U$ \\
\hline A-15 & TR-D & 0.676 & 0.681 & - & 700 & - & $1 \cdot 32$ & - & U \\
\hline SA-10 & TR-D & 0.748 & 0.795 & - & 100 & - & $1 \cdot 56$ & - & $\mathrm{T}$ \\
\hline SA-11 & TR-D & 0.751 & 0.774 & - & 200 & - & 1.53 & - & $\mathrm{T}$ \\
\hline SA-12 & TR-D & 0.742 & 0.769 & - & 300 & - & 1.47 & - & $\mathrm{T}$ \\
\hline SA-13 & TR-D & 0.711 & 0.724 & - & 700 & - & $1 \cdot 42$ & - & $\mathrm{T}$ \\
\hline SA-14 & TR-UCS & 0.770 & - & - & - & - & - & 85 & $\mathrm{~T}$ \\
\hline SA-15 & TR-UCS & 0.750 & - & - & - & - & - & 72 & $\mathrm{~T}$ \\
\hline
\end{tabular}

DS, direct shear test; TR-D, drained triaxial test; TR-UCS, unconfined compression test; $U$, untreated specimen; T, treated specimen 


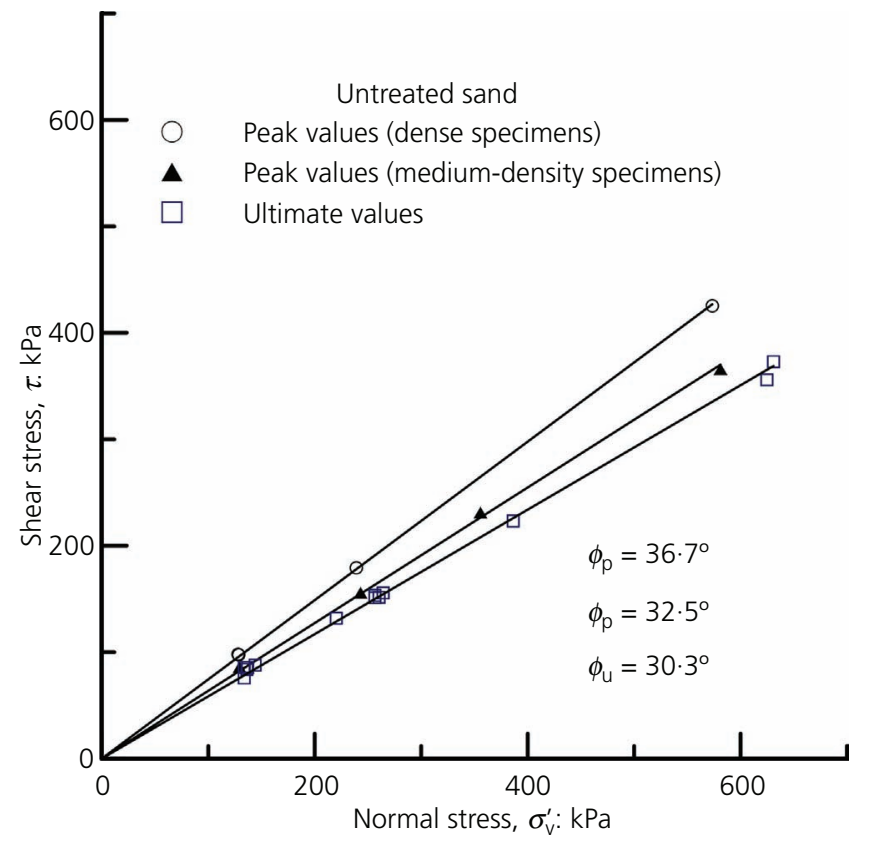

Figure 4. Strength envelopes for M31 sand: peak and ultimate strength conditions in direct shear tests

treated loose sand is considered as equivalent to dense untreated sand (Porcino et al., 2012). In Figure 6, the response of a dense sand specimen, shown as a broken line, may be considered comparable to that of the loose treated sand in terms of dilation, albeit their distinctive differences in terms of initial contraction, peak dilatancy rate and final dilation. It is interesting to note that for dense sand under low vertical stress, the vertical displacement approximates the mean grain diameter; for the treated sand even at loose state, the vertical displacement overpasses this limit indicating that assemblies of particles may be involved in the dilation process as the load-transferring chains rearrange during shearing.

The continuous decrease in peak stress ratio $\tau / \sigma_{\mathrm{v}}^{\prime}$ observed for the treated sand with increasing stress level, within the examined range of $\sigma_{\mathrm{v} 0}^{\prime}=125-555 \mathrm{kPa}$, is consistent with the notion of continual structural degradation at the interparticle level and within the pores. A similar observation was made by Porcino et al. (2012) for drained triaxial tests, where an increase in peak stress ratio of the treated compared to untreated sand was evidenced for stress levels lower than $100 \mathrm{kPa}$. The highest stress level in these tests was $300 \mathrm{kPa}$ which was not high enough to highlight the continuing drop in the peak stress ratio indicated by the test at $555 \mathrm{kPa}$ presented herein. The above observation, given that the same peak stress ratio is attained for the untreated sand specimens with the same density irrespective of stress level, leads to the conclusion that treated specimens are stronger and considerably more dilative than the untreated specimens, their difference decreasing with increasing stress level.

The increase in peak stress ratio with decreasing normal stress observed in treated sand specimens indicates that the peak strength envelope is curved in the lower stress range. In Figure 7,

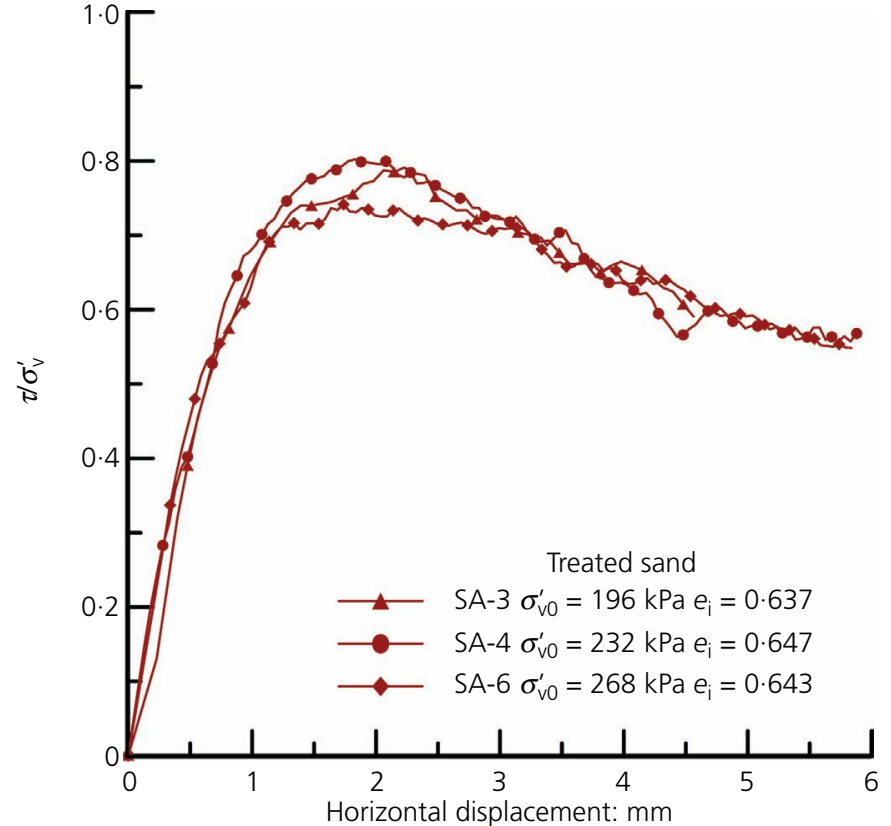

(a)

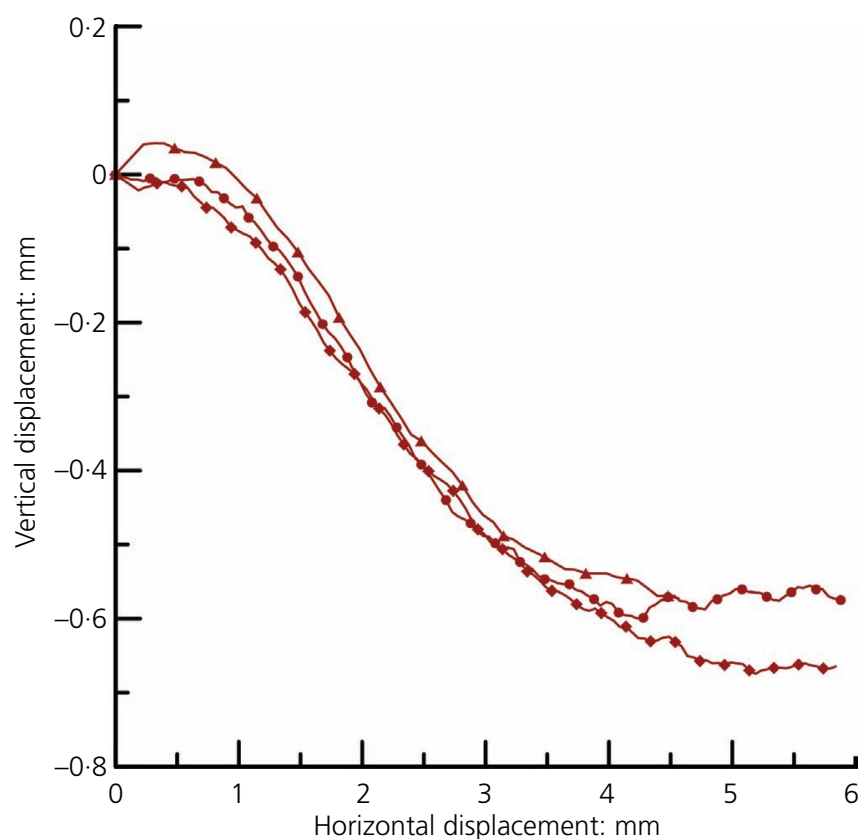

(b)

Figure 5. Direct shear tests on treated M31 sand: (a) stress ratio $\tau / \sigma_{v}^{\prime}$ against horizontal displacement curves; (b) vertical against horizontal displacement curves 


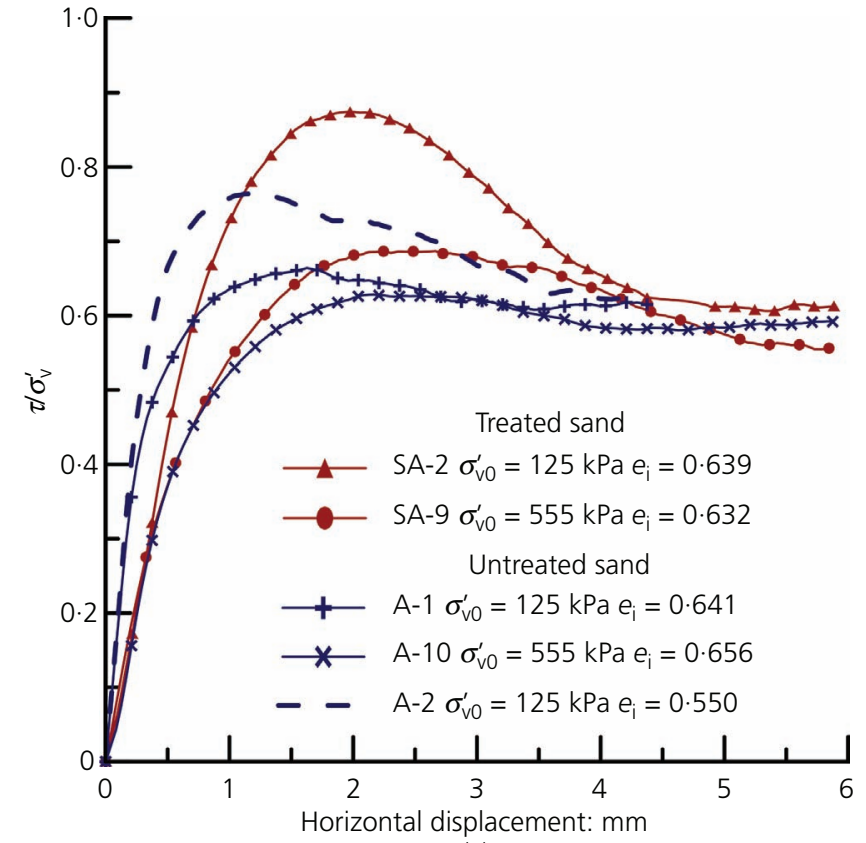

(a)

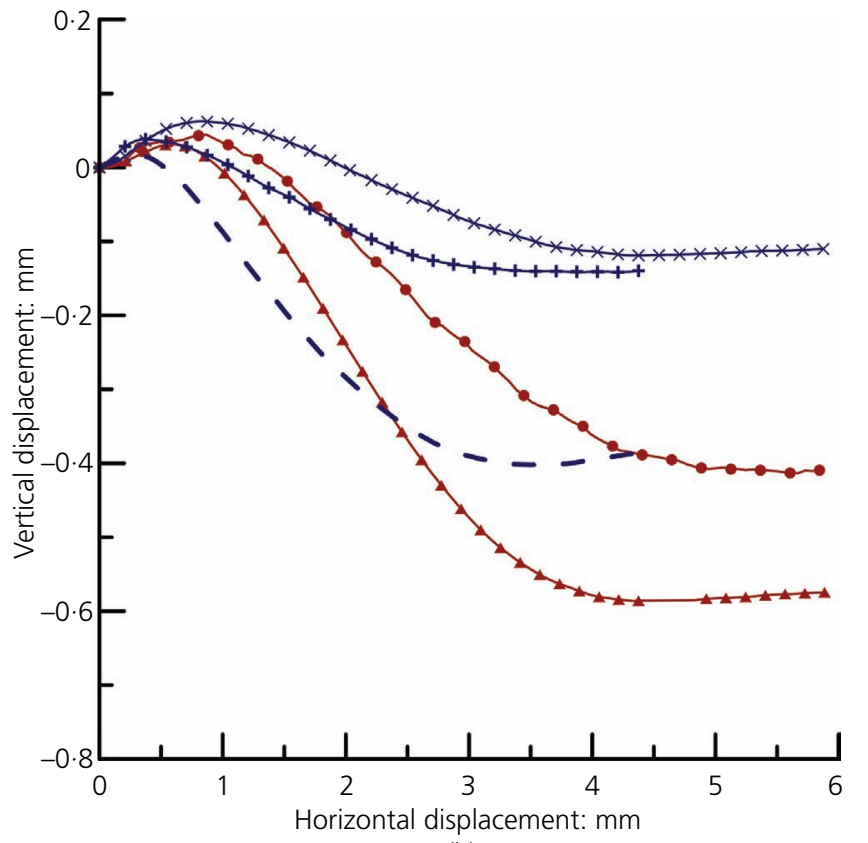

(b)

Figure 6. Direct shear tests on treated and untreated M31 sands: (a) stress ratio $\tau / \sigma_{v}^{\prime}$ against horizontal displacement curves; (b) vertical against horizontal displacement curves

the best-fit line indicates negligible apparent cohesion intercept, while the Mohr-Coulomb strength envelope has a higher slope at lower stresses; the angle of shearing resistance is stress level dependent with a value of $\phi_{\mathrm{p}}=41 \cdot 3^{\circ}$ at $\sigma_{\mathrm{v} 0}^{\prime}=125 \mathrm{kPa}$ and a

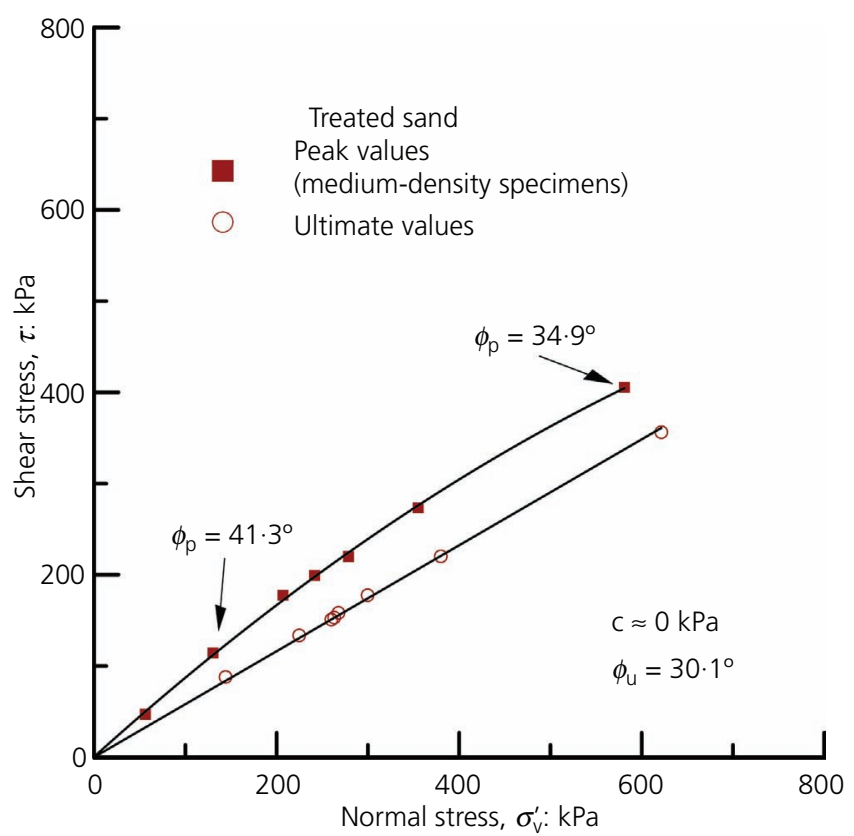

Figure 7. Strength envelopes for treated M31 sand: peak and ultimate strength conditions in direct shear tests secant value of $\phi_{\mathrm{p}}=34.9^{\circ}$ at $\sigma_{\mathrm{v} 0}^{\prime}=555 \mathrm{kPa}$, compared with $\phi_{\mathrm{p}}=$ $32.5^{\circ}$ observed for sand in Figure 4. This is reminiscent of the strength envelopes for rock joint strength where the asperities along rock joints play an important role at low stresses, which is diminished at higher stresses (Barton, 1973); it may be postulated that as the stress and strain level increases, the support provided by the CS aqueous gel at interparticle and intrapore levels diminishes continually. This is backed up by the fact that at ultimate strength conditions, the strength envelopes coincide for untreated and treated sands (Figure $4 \mathrm{cf}$. Figure 7); the strength parameters are indicated in the figures - that is, $c=0$ and $\phi_{\mathrm{u}}=$ $30 \cdot 3-30 \cdot 1^{\circ}$. At ultimate strength conditions, sand-to-sand contact is maintained; hence, the same stress ratio is obtained for treated and untreated specimens, albeit at a lower density for the latter.

However, it should be stressed that at all stress levels, the presence of the CS gel within the pores of the sand grain skeleton resists contraction and precipitates dilation by forcing the grains forming the load-transferring chains to rearrange to a looser state with shearing. The treated sand at the same initial density as the untreated sand shows dramatically increased dilatancy rates at peak strength.

The previously mentioned observations are supported by the drained triaxial tests on treated sand, shown in Figure 8(a) in terms of stress ratio $q / p^{\prime}$ against the axial strain for a range of confining stresses. Drained tests were performed under a range of back pressures, and the results are independent of the magnitude of back pressure; the tests shown in the figure were performed at 
Mechanical behaviour of sand stabilised

with colloidal silica

Georgiannou, Pavlopoulou and Bikos

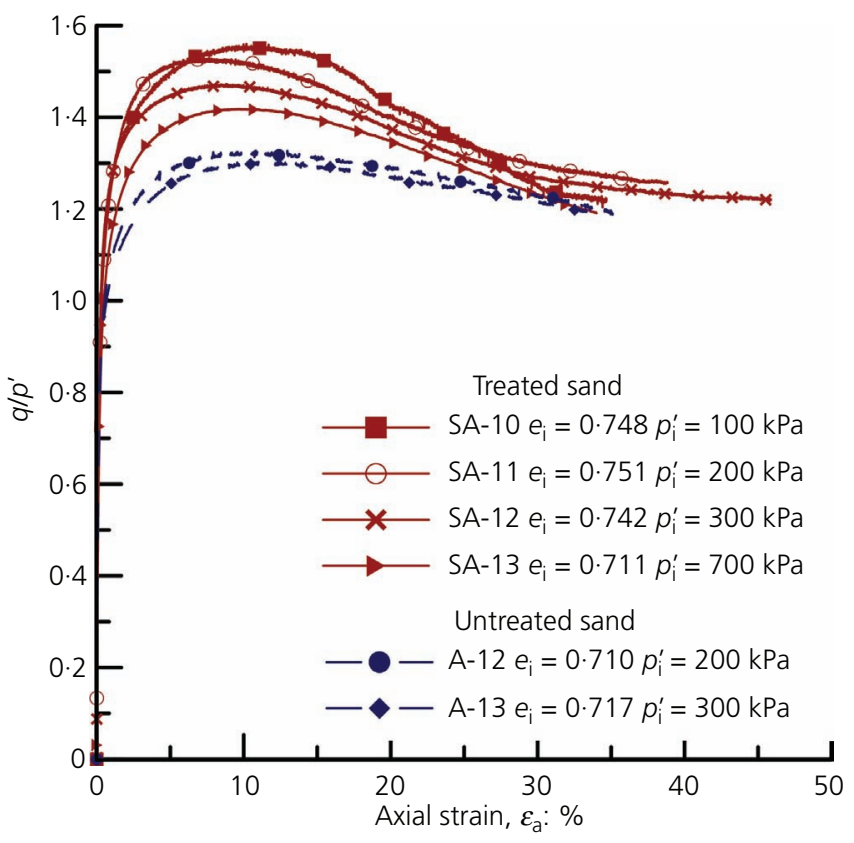

(a)

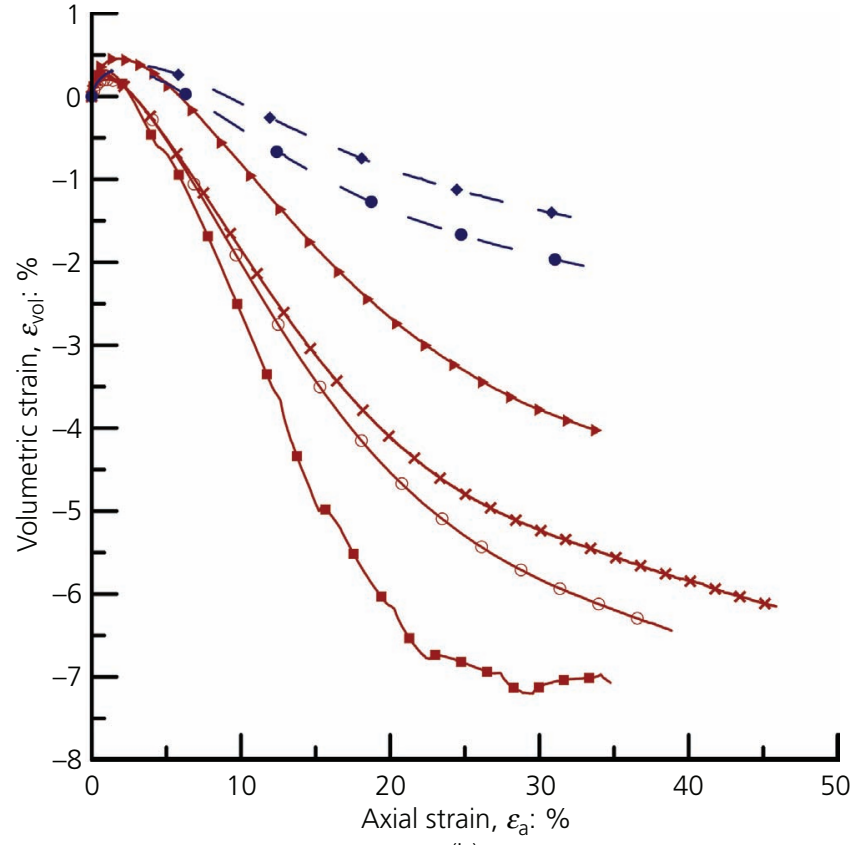

(b)

Figure 8. Drained triaxial tests on treated and untreated M31 sands: (a) stress ratio q/p' against axial strain curves; (b) volumetric strain against axial strain curves

a back pressure of $700 \mathrm{kPa}$. Details of the specimens are included in Table 1. The peak stress ratio appears to be stress level dependent in a similar fashion to direct shear box tests - that is, decreasing with increasing stress level. Within the same stress range, the untreated sand exhibits a common lower value of $q / p^{\prime}=$ 1·31. In Figure 8(b), volumetric strain changes confirm the above observation. The corresponding curves for untreated loose sand have been included in the figure as broken lines and show significantly lower dilation as observed earlier in Figure 6(b). The failure envelopes for the drained triaxial tests, included in Table 1, on treated (SA-10, SA-11, SA-12, SA-13) and untreated (A-12, A-13, A-14, A-15) sand specimens are shown in Figure 9; the envelope is non-linear for the treated sand but is not markedly curved compared to direct shear tests at lower stresses (Figure 7). For the sand, a value of $\phi_{\mathrm{p}}=32 \cdot 5^{\circ}$ similar to that obtained in the shear box tests is observed in Figures 9 and 4, respectively. For the loose treated sand, the corresponding angle of shearing resistance has a secant value of $\phi_{\mathrm{p}}=35.0^{\circ}$ at $p_{\mathrm{i}}^{\prime}=700 \mathrm{kPa}$; a cohesion intercept approximately equal to $c=14 \mathrm{kPa}$ should be viewed with caution due to lack of data at low confinement.

In Figures 10(a) and 10(b), typical stress-dilatancy relationships are shown for the treated and untreated sands under direct shear at $\sigma_{\mathrm{v} 0}^{\prime}=125 \mathrm{kPa}$ and triaxial testing at $p_{\mathrm{i}}^{\prime}=700 \mathrm{kPa}$, the former expressed as $-\mathrm{d} y / \mathrm{d} x$ against $\tau / \sigma_{\mathrm{v}}^{\prime}$ and the latter as $-\mathrm{d} \varepsilon_{\mathrm{vol}} / \mathrm{d} \varepsilon_{\mathrm{a}}$ against $q / p^{\prime}$. The peak stress ratio and maximum dilatancy occur simultaneously, indicating the lack of cementation bonding (Cuccovillo and Coop, 1999). The peak dilatancy ratio is plotted against $\sigma_{\mathrm{v}}^{\prime}$ for direct shear tests in Figure 11(a) and against the mean effective stress for drained triaxial tests in Figure 11(b). For a wide stress range, the ratio remains higher for treated sand. However, under both loading modes, the peak dilatancy ratio continuously decreases with stress level towards the nearlyconstant value observed for the untreated sand.

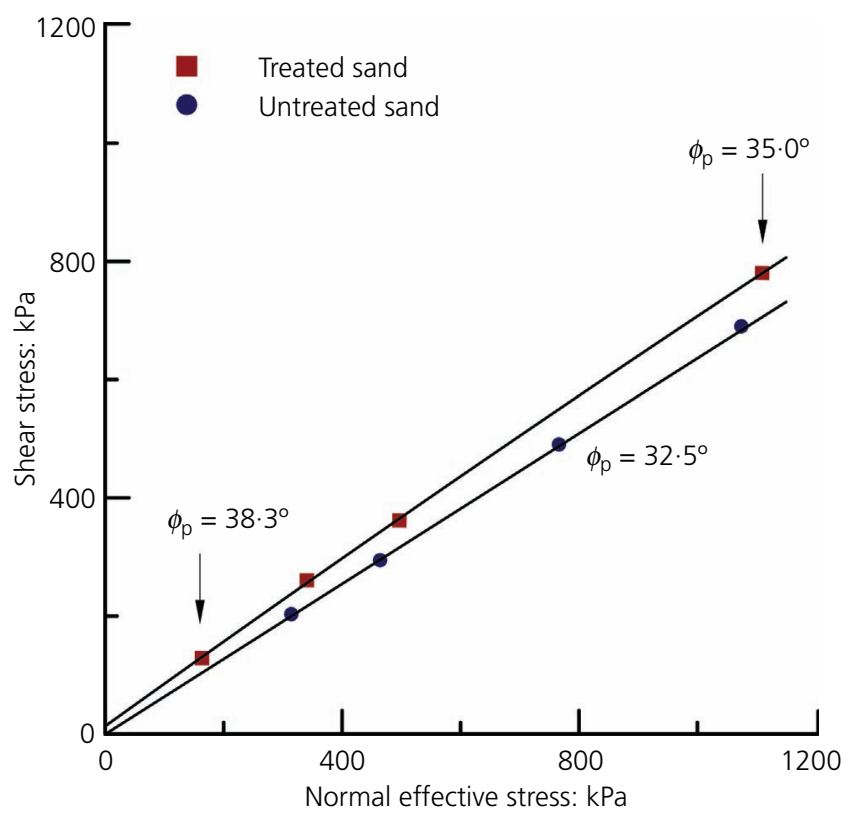

Figure 9. Peak strength envelopes: drained triaxial tests on treated and untreated M31 sands 


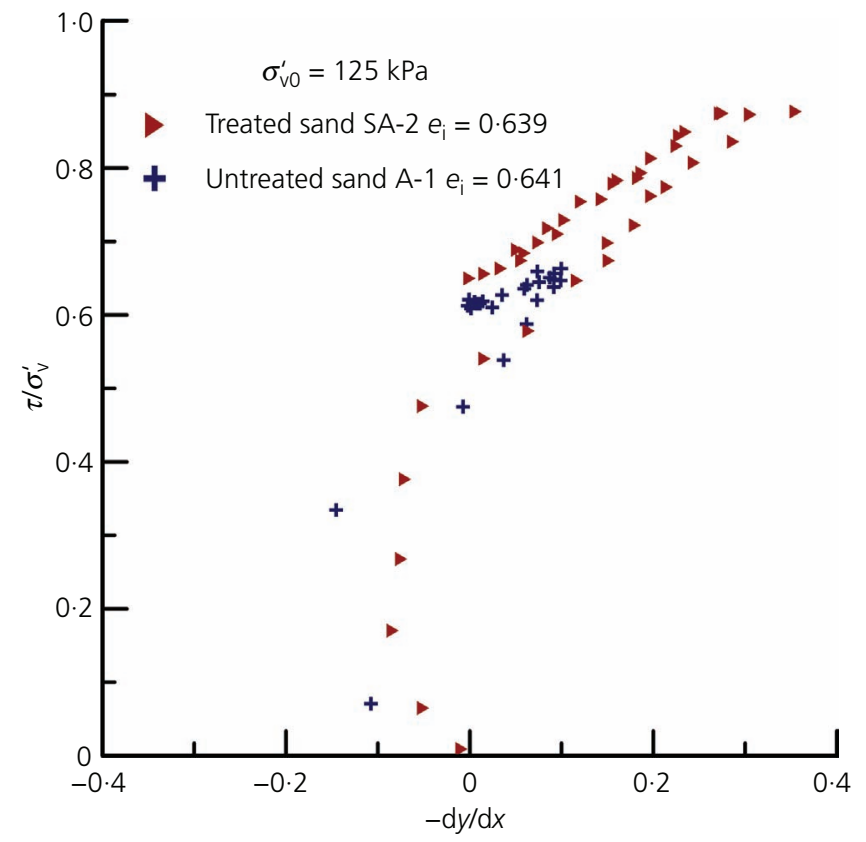

(a)

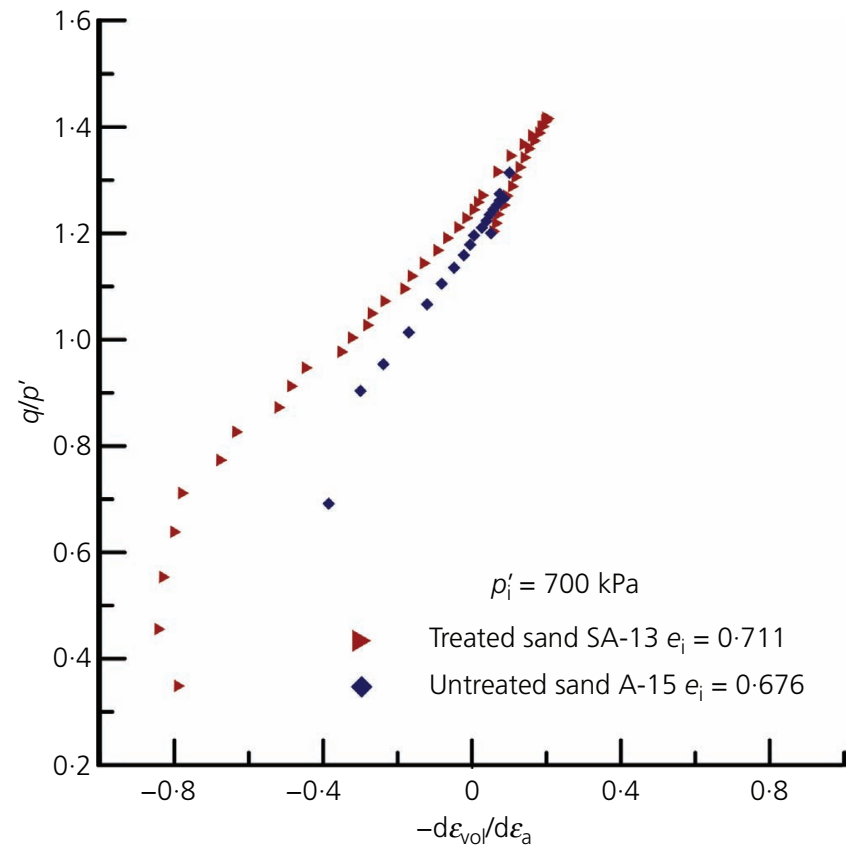

(b)

Figure 10. Stress-dilatancy curves for treated and untreated M31 sands: (a) direct shear tests; (b) drained triaxial tests

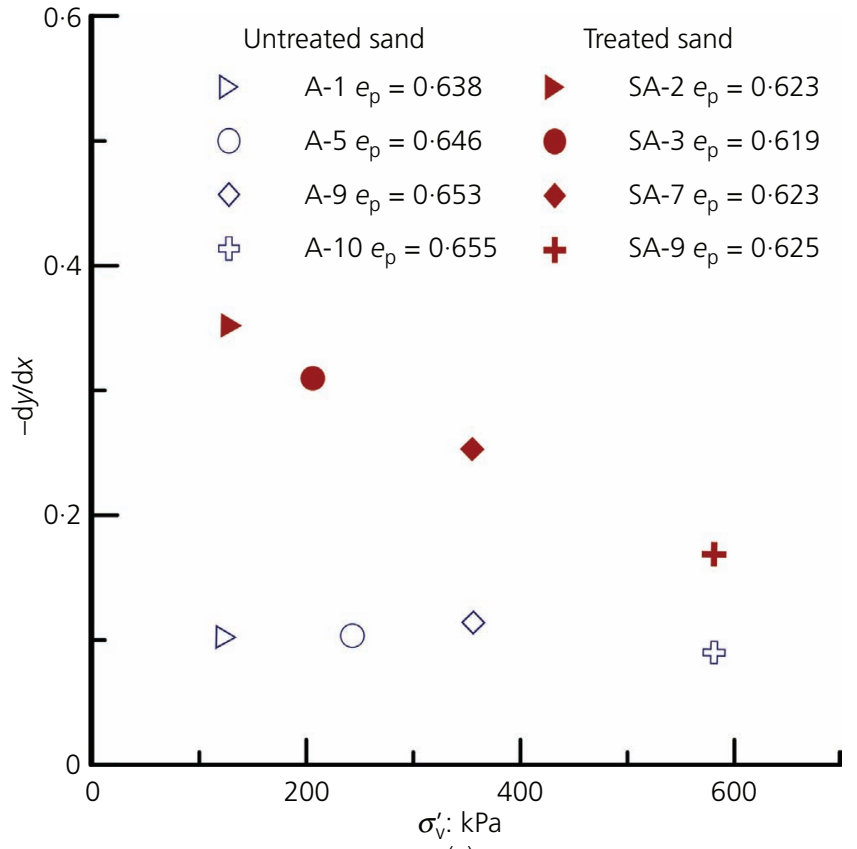

(a)

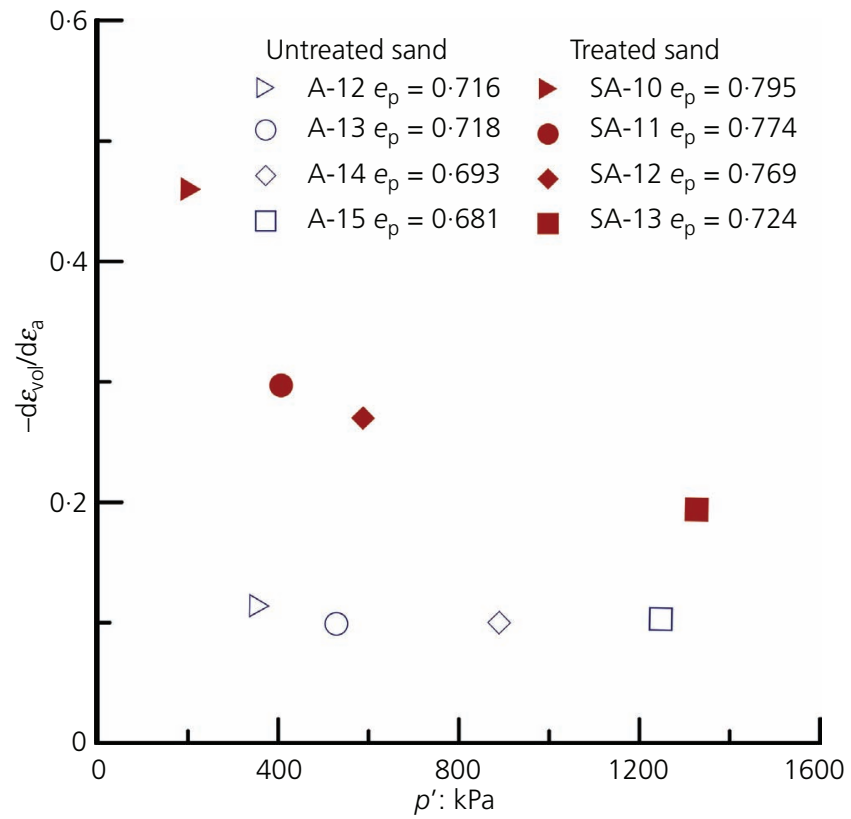

(b)

Figure 11. Peak dilatancy ratio against stress level: (a) direct shear tests; (b) drained triaxial tests

For the treated sand, when considering the decrease in peak stress ratio observed earlier, associated with the previously mentioned decrease in peak dilatancy ratio with increasing stress level, structural degradation may be inferred. To assess structural degradation, the normal compression in the oedometer is compared to the isotropic compression in the triaxial apparatus. In Figure 12(a), the isotropic compression of the treated sand induces similar deformations as with the untreated sand. However, for the treated sand, normal compression loading in the oedometer results in significantly increased vertical deformations compared 


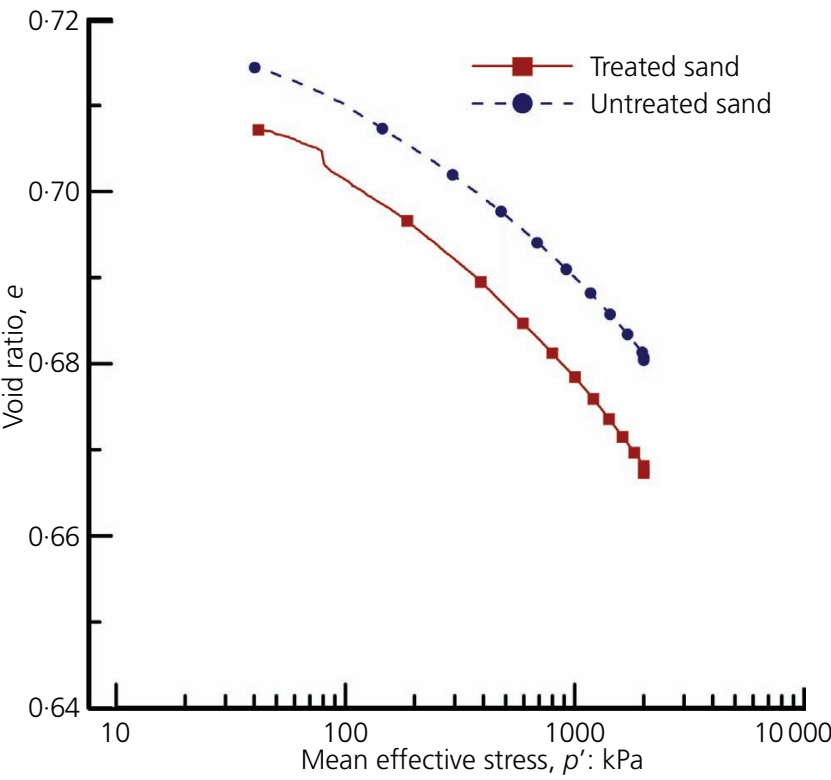

(a)

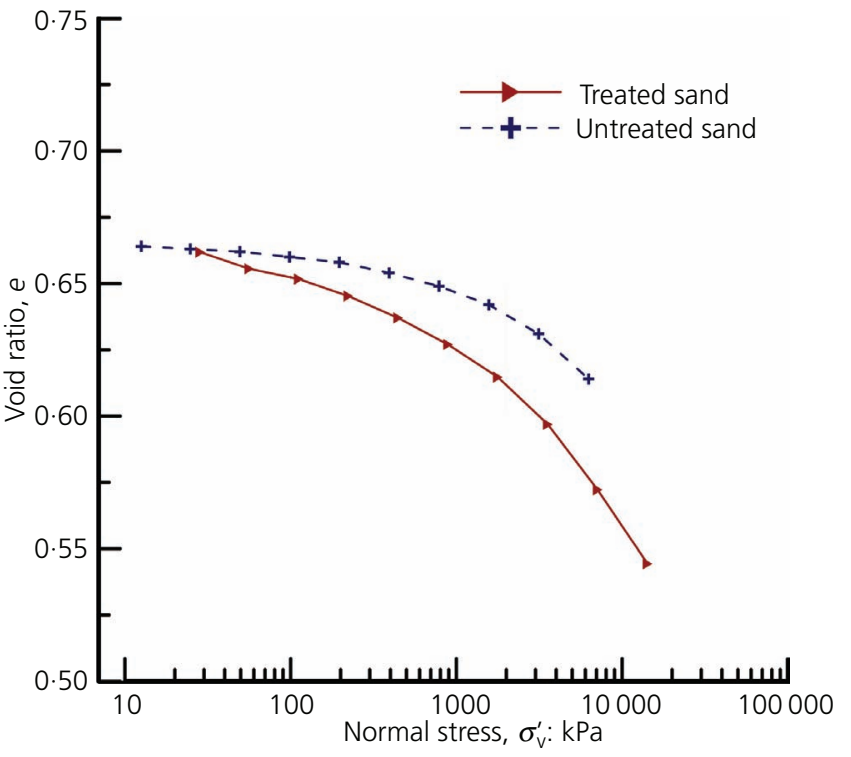

(b)

Figure 12. Normal compression tests: (a) isotropic compression; (b) 1D compression

to untreated sand with the same density, as indicated in Figure 12(b). Sand grains attain a denser packing in the presence of the gel, which appears to facilitate densification. It is interesting that isotropic compression restricts this excessive movement of the sand grains; it is possible that the structure of the gel-supported sand is weaker under anisotropic loading conditions, but this requires further investigation, which is beyond the scope of the current paper.

The nature of the aqueous gel is considered to account for the initially contradictory behaviour of the treated sand - that is, extreme dilation in shearing against increased compressibility under normal compression loading. It has been reported in the literature that the aqueous gel can be easily damaged but has a self-healing ability (Brinker and Scherer, 1990; Vigil et al., 1994). When combined with the high potential of the CS to absorb water (Bergna and Roberts, 2005), the response of the aqueous gel (hydrogel) to the structural rearrangement imposed during shearing, which involves clusters of sand particles supported by the gel in and around the pores tending to override each other, is to absorb water available in drained tests. When it is rapidly compressed under drained conditions in the oedometer, the compression curve shows significant curvature associated with structural breakdown; as the gel is being damaged, free water is pushed out of the pores. When yielding has fully developed at a high stress level, the sand has attained its densest state. The sand grain structure under normal compression is more unstable compared to the untreated sand; the presence of gel at interparticle contact may facilitate slippage between sand particles. Georgiannou (2006) observed a similar effect; when platy particles are introduced at the contacts between sand grains, the stability of the sand-clay mixtures is greatly reduced.

Figure 13 shows optical micrographs of the treated sand specimens. In Figure 13(a), the presence of hydrogel at interparticle contacts may be inferred, as it covers the space between the sand particles at the bottom (A) and top (B) of the micrograph. Furthermore, in Figure 13(b), the gel has been airdried; the air-dried xerogel appears to lay at most sand grain contacts. The air-dried xerogel can be contrasted with the hydrogel in Figure 13(a), the former being cracked due to inhomogeneous shrinkage-induced stresses, the latter maintaining the capacity to absorb and/or discharge free water during mechanical loading.

\section{Conclusions}

Sand at a loose state treated with CS gel shows extreme dilation, roughly comparable with a very dense sand. The peak stress ratio mobilised during shearing of the treated sand significantly increases with decreasing stress level resulting in a curved peak strength envelope at lower stress levels. Hence, at lower stress levels, the increase in the mobilised stress ratio at peak strength enhances the shearing resistance of the treated sand. At higher stress levels, the peak stress ratios remain higher compared to untreated sand, but the increase becomes less significant, while the same stress ratio is mobilised at ultimate strength conditions by treated and untreated sands. Peak strength is associated with peak dilatancy ratios increased by two to four times compared to sand of similar density depending on stress level. In contrast, under normal compression, the treated sand is easily densified, 

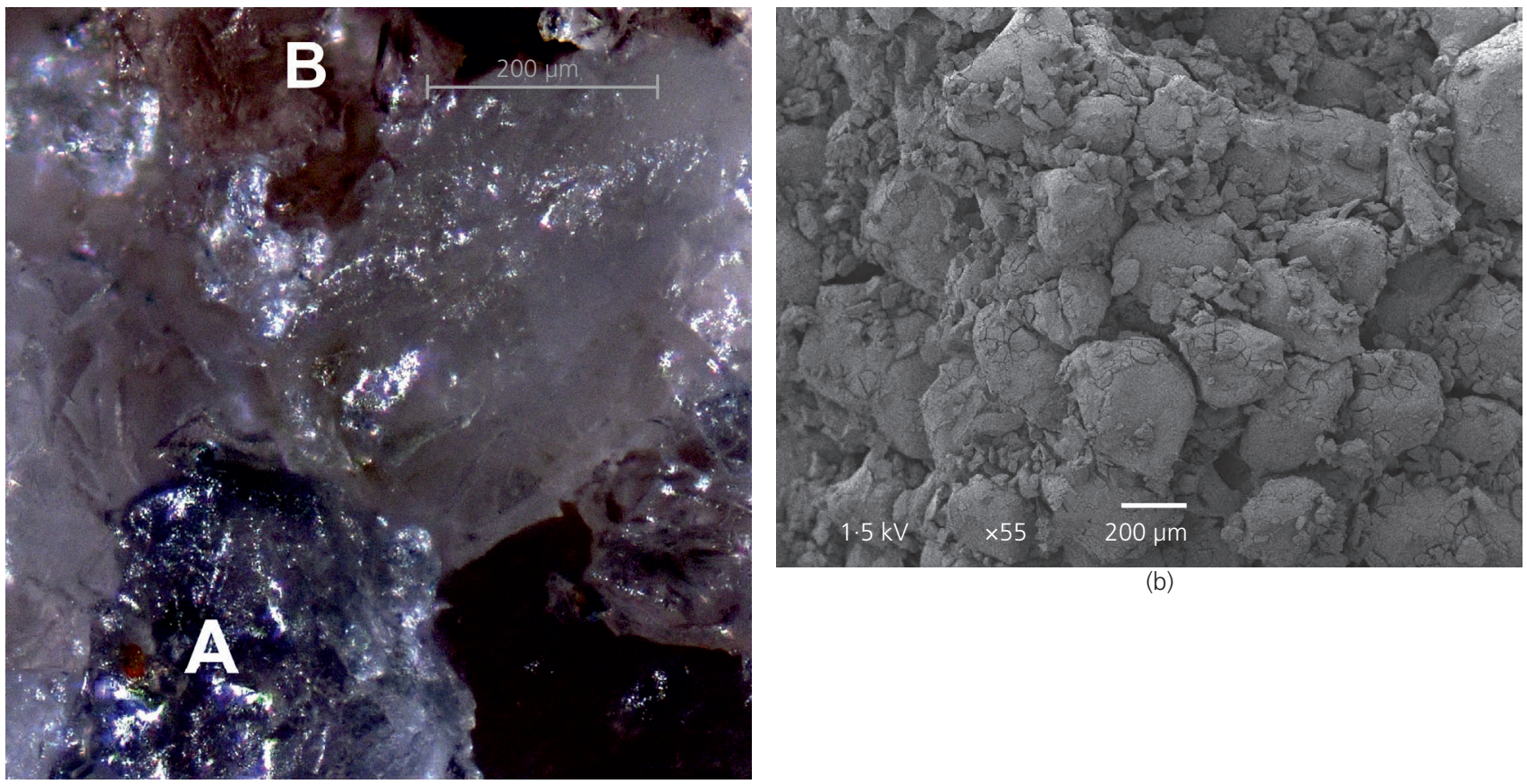

(b)

(a)

Figure 13. Optical micrographs showing treated sand specimens in (a) wet and (b) dry conditions

exhibiting higher compressibility than sand of similar density. In this study, the ability of the hydrogel to absorb and discharge water depending on loading conditions is demonstrated suggesting that volume change and/or pore pressure measurement is paramount to describe the response of stabilised sands.

\section{Acknowledgements}

This research was co-financed by the EU (European Social Fund) and Greek national funds through the Operational Programme 'Education and Lifelong Learning' of the National Strategic Reference Framework-Research Funding Program: Thales Investing in Knowledge Society through the European Social Fund.

\section{REFERENCES}

Agapoulaki GI and Papadimitriou AG (2015) Rheological properties of colloidal silica as a means for designing passive stabilization of liquefiable soils. In Proceedings: XVI European Conference on Soil Mechanics and Geotechnical Engineering (Winter MG, Smith DM, Eldred PJL and Toll DG (eds)). Institution of Civil Engineers, London, UK, vol. 5, pp. 2331-2336, http://dx.doi.org/10.1680/ecsmge.60678.vol5.356.

Bareither CA, Benson CH and Edil TB (2008) Reproducibility of direct shear tests conducted on granular backfill materials. Geotechnical Testing Journal 31(1): 1-11, http://dx.doi.org/10.1520/GTJ100878.

Barton NR (1973) Review of a new shear strength criterion for rock joints. Engineering Geology 7(4): 287-332, http://dx.doi.org/10.1016/ 0013-7952(73)90013-6.

Bergna HE and Roberts WO (eds) (2005) Colloidal Silica: Fundamentals and Applications. CRC, Boca Raton, FL, USA.

Brinker CJ and Scherer GW (eds) (1990) Sol-Gel Science: the Physics and Chemistry of Sol-Gel Processing. Academic Press, Cambridge, MA, USA.
Cuccovillo T and Coop MR (1999) On the mechanics of structured sands. Géotechnique 49(6): 741-760, http://dx.doi.org/10.1680/geot.1999.49. 6.741.

D'Appolonia E, Miller CE and Ware TM (1955) Sand compaction by vibroflotation. Transactions of the American Society of Civil Engineers 120(1): 154-168.

Díaz-Rodríguez JA, Antonio-Izarraras VM, Bandini P and López-Molína JA (2008) Cyclic strength of a natural liquefiable sand stabilized with colloidal silica grout. Canadian Geotechnical Journal 45(10): 1345-1355, http://dx.doi.org/10.1139/T08-072.

Donovan NC, Becker AM and Lau GY (1984) Liquefaction mitigation by site improvement - a case study. In Proceedings of the 8th World Conference on Earthquake Engineering. Prentice Hall, Englewood Cliffs, NJ, USA, vol. 1, pp. 693-700.

Finn WDL and Vaid YP (1977) Liquefaction potential from drained constant volume cyclic simple shear tests. In Proceedings of the 6th World Conference on Earthquake Engineering. Sarita Prakashan, Meerut City, India, vol. 6, pp. 7-12.

Gallagher PM and Mitchell JK (2002) Influence of colloidal silica grout on liquefaction potential and cyclic undrained behavior of loose sand. Soil Dynamics and Earthquake Engineering 22(9-12): 1017-1026, http://dx.doi.org/10.1016/S0267-7261(02)00126-4.

Gallagher PM, Conlee CT and Rollins KM (2007) Full-scale field testing of colloidal silica grouting for mitigation of liquefaction risk. Journal of Geotechnical and Geoenvironmental Engineering 133(2): 186-196, http://dx.doi.org/10.1061/(ASCE)1090-0241(2007)133:2(186).

Georgiannou VN (2006) The undrained response of sands with additions of particles of various shapes and sizes. Géotechnique 56(9): 639-649, http://dx.doi.org/10.1680/geot.2006.56.9.639.

Georgiannou VN and Tsomokos A (2008) Comparison of two fine sands under torsional loading. Canadian Geotechnical Journal 45(12): 1659-1672, http://dx.doi.org/10.1139/T08-083.

Kodaka T, Oka F, Ohno Y, Takyu T and Yamasaki N (2005) Modeling of cyclic deformation and strength characteristics of silica treated sand. In 
Geotechnical Research

Volume 4 Issue GR1
Mechanical behaviour of sand stabilised

with colloidal silica

Georgiannou, Pavlopoulou and Bikos
Geomechanics: Testing, Modeling, and Simulation (Yamamuro JA and Koseki J (eds)). American Society of Civil Engineers, Reston, VA, USA, Geotechnical Special Publication 143, pp. 205-216.

Maher MH, Ro S and Welsh JP (1994) Cyclic undrained behavior and liquefaction potential of sand treated with chemical grouts and microfine cement (MC-500). Geotechnical Testing Journal 17(2): 159-170, http://dx.doi.org/10.1520/GTJ10088J.

Mayne PW, Jones JS Jr. and Dumas JC (1984) Ground response to dynamic compaction. Journal of Geotechnical Engineering 110(6): 757-774, http://dx.doi.org/10.1061/(ASCE)0733-9410(1984)110:6(757).

Porcino D, Marcianò V and Granata R (2011) Undrained cyclic response of a silicate-grouted sand for liquefaction mitigation purposes. Geomechanics and Geoengineering: an International Journal 6(3): 155-170, http://dx.doi.org/10.1080/17486025.2011.560287.

Porcino D, Marcianò V and Granata R (2012) Static and dynamic properties of a lightly cemented silicate-grouted sand. Canadian Geotechnical Journal 49(10): 1117-1133, http://dx.doi.org/10.1139/ T2012-069.

Seed HB and Lee KL (1966) Liquefaction of saturated sands during cyclic loading. Journal of the Soil Mechanics and Foundations Division 92(SM6): 105-134.
Seed HB, Idriss IM, Makdisi FI and Banerjee NG (1975) Representation of Irregular Stress Time Histories by Equivalent Uniform Stress Series in Liquefaction Analyses. Earthquake Engineering Research Center, University of California, Berkeley, CA, USA, Report No. EERC 75-29.

Towhata I and Kabashima Y (2001) Mitigation of seismically - induced deformation of loose sandy foundation by uniform permeation grouting. Proceedings of the Fifteenth International Conference on Soil Mechanics and Geotechnical Engineering, Earthquake Geotechnical Engineering Satellite Conference, Istanbul, Turkey, pp. 313-318.

Vaid Y, Sivathayalan S and Stedman D (1999) Influence of specimenreconstituting method on the undrained response of sand. Geotechnical Testing Journal 22(3): 187-195, https://dx.doi.org/10.1520/ GTJ11110J.

Vigil G, Xu Z, Steinberg S and Israelachvili J (1994) Interactions of silica surfaces. Journal of Colloid and Interface Science 165(2): 367-385, http://dx.doi.org/10.1006/jcis.1994.1242.

Wang YH and Leung SC (2008) Characterization of cemented sand by experimental and numerical investigations. Journal of Geotechnical and Geoenvironmental Engineering 134(7): 992-1004, http://dx.doi. org/10.1061/(ASCE)1090-0241(2008)134:7(992).

\section{How can you contribute?}

To discuss this paper, please submit up to 500 words to the editor at journals@ice.org.uk. Your contribution will be forwarded to the author(s) for a reply and, if considered appropriate by the editorial board, it will be published as a discussion in a future issue of the journal. 